\title{
SALUD
}

\section{Reporte de caso: diagnóstico retrasado de dengue en paciente con lupus eritematoso sistémico}

\author{
Cynthia Bernal ${ }^{1}$, Isabel Acosta ${ }^{2}$, Fátima Cardozo ${ }^{3}$, César Cantero, \\ Jesse Waggoner ${ }^{4}$, María Eugenia Acosta ${ }^{1}$, Laura Arias ${ }^{1}$, Yvalena de \\ Guillén', Laura Mendoza³ ${ }^{3}$ Malvina Páez³ ${ }^{3}$ Margarita Duarte², Alejandra \\ Rojas $^{1}$
}

\section{Resumen}

Introducción: El dengue, causado por el virus del dengue (DENV), se encuentra entre las enfermedades causadas por arbovirus más importantes del mundo y en Paraguay, representa un importante problema de salud pública. Existen estudios que indican que los pacientes con enfermedades autoinmunes y una infección aguda por DENV pueden presentar un cuadro clínico complicado.

Objetivo: Describir el caso de una mujer de 43 años con diagnóstico de lupus eritematoso sistémico (LES) que presentó un cuadro de dengue grave en 2018. La paciente fue diagnosticada con LES en 2011 debido a manifestaciones articulares y síndrome de Kikuchi, se mantuvo en tratamiento estable con micofenolato, hidroxicloroquina y prednisona en dosis bajas. Diez días antes de la presentación al hospital, la paciente desarrolló una fiebre subjetiva con artralgias, mialgias y diarrea que mejoraron con el tratamiento ambulatorio. El día de presentación e ingreso al hospital, la paciente notificó fiebre alta (40ㅡ) $)$, cefalea, artralgias, mialgias, náuseas y vómitos. Las pruebas de laboratorio revelaron trombocitopenia $(128,000 / \mathrm{uL})$, pero resultados negativos para el antígeno NS1 de DENV (prueba rápida) e IgM anti-DENV (ELISA de captura). Dos días después, se realizaron pruebas para detectar IgM contra el virus chikungunya con resultado negativo. Debido a la alta sospecha clínica, se

\footnotetext{
1 Universidad Nacional de Asunción. Instituto de Investigaciones en Ciencias de la Salud. Departamento de Producción.

2 Universidad Nacional de Asunción. Facultad de Ciencias Médicas. Hospital de Clínicas. Departamento de Reumatología.

3 Universidad Nacional de Asunción. Instituto de Investigaciones en Ciencias de la Salud. Departamento de Salud Pública.

4 Emory University School of Medicine. Division of Infectious Diseases. Department of Medicine. La investigación fue apoyada por una beca del Consejo Nacional de Ciencia y Tecnología (CONACYT) de Paraguay, otorgada como parte del Programa de Vinculación de Científicos y Tecnólogos (PVCT 16-66).

Este trabajo fue presentado en el XXIX Congreso Brasilero de Virología y XIII Encuentro de Virología del MERCOSUR en octubre de 2018, en donde también fue publicado el resumen en inglés.

E-mail: bernalcynthiaq@gmail.com
}

DOI: 10.26885/rcei.foro.2018.120 


\section{Diagnóstico retrasado de dengue en paciente con lupus eritematoso. Bernal et al.}

volvieron a realizar tests de diagnóstico de dengue. Las pruebas fueron negativas para NS1 de DENV (prueba rápida) y ARN de DENV por RT-PCR en tiempo real. Sin embargo, los resultados para IgM y IgG anti-DENV (prueba rápida) fueron positivos. Después de dos días, se confirmó la presencia de IgM anti-DENV mediante ELISA de captura. Una radiografía de tórax y tomografía computarizada mostraron infiltrados pulmonares bilaterales leves, derrame pleural bilateral y un pequeño derrame pericárdico, compatible con un diagnóstico de dengue grave. Una semana después del ingreso, la paciente mostró una mejoría en los síntomas y en la trombocitopenia. No hubo evidencia de una exacerbación de los síntomas de LES durante la enfermedad aguda. En la literatura, se han descrito casos en los que el diagnóstico de LES se vio retrasado debido a la confusión creada por una infección aguda de DENV. Sin embargo, la situación opuesta se describe aquí, donde el diagnóstico de dengue se complicó por un diagnóstico preexistente de LES. La detección de anticuerpos específicos pudo haberse retrasado debido al tratamiento inmunosupresor y los síntomas iniciales pudieron haberse atribuido a un brote de LES. Este caso revela la importancia de una alta sospecha clínica y pruebas de seguimiento para el dengue en pacientes con enfermedades autoinmunes y tratamiento inmunosupresor.

Palabras clave: enfermedades autoinmunes, dengue grave, lupus.

\section{Referencias}

De Souza, S. et al. (2010). J Clin Rheumatol. 16, 47-48.

Oliveira, S. et al. (2012). Crit Care Med. 40, 1-328.

Santosa, A. et al. (2012). Scand J Rheumatol. 41, 77-79.

Talib, S. et al. (2013). Int Med Case Rep J. 6, 71-75.

Verdolin, L. D. et al. (2014). Rev Bras Reumatol. 54, 318-321. 